\title{
Chronic White Matter Inflammation and Serum Neurofilament Levels in Multiple Sclerosis
}

Pietro Maggi, MD, PhD,* Jens Kuhle, MD, PhD,* Sabine Schädelin, MSc, Franziska van der Meer, PhD, Matthias Weigel, PhD, Riccardo Galbusera, MD, Amandine Mathias, PhD, Po-Jui Lu, MSc, Reza Rahmanzadeh, MD, Pascal Benkert, PhD, Francesco La Rosa, MSc, Meritxell Bach Cuadra, PhD, Pascal Sati, PhD, Marie Théaudin, MD, Caroline Pot, MD, PhD, Vincent van Pesch, MD, PhD, David Leppert, MD, Christine Stadelmann, MD, Ludwig Kappos, MD, Renaud Du Pasquier, MD, Daniel S. Reich, MD, PhD, Martina Absinta, MD, PhD,* and Cristina Granziera, MD, PhD*

Neurology ${ }^{\circledR}$ 2021;97:e543-e553. doi:10.1212/WNL.0000000000012326

\section{Abstract}

\section{Objective}

To assess whether chronic white matter inflammation in patients with multiple sclerosis (MS) as detected in vivo by paramagnetic rim MRI lesions (PRLs) is associated with higher serum neurofilament light chain (sNfL) levels, a marker of neuroaxonal damage.

\section{Methods}

In 118 patients with MS with no gadolinium-enhancing lesions or recent relapses, we analyzed 3D-submillimeter phase MRI and sNfL levels. Histopathologic evaluation was performed in 25 MS lesions from 20 additional autopsy MS cases.

\section{Results}

In univariable analyses, participants with $\geq 2$ PRLs $(n=43)$ compared to those with $\leq 1$ PRL ( $n$ $=75$ ) had higher age-adjusted sNfL percentiles (median, 91 and 68; $p<0.001$ ) and higher Multiple Sclerosis Severity Scale scores (MSSS median, 4.3 and 2.4; $p=0.003$ ). In multivariable analyses, sNfL percentile levels were higher in PRLs $\geq 2$ cases ( $\beta_{\text {add }}, 16.3 ; 95 \%$ confidence interval $[\mathrm{CI}], 4.6-28.0 ; p<0.01$ ), whereas disease-modifying treatment (DMT), Expanded Disability Status Scale (EDSS) score, and T2 lesion load did not affect sNfL. In a similar model, sNfL percentile levels were highest in cases with $\geq 4$ PRLs ( $n=30 ; \beta_{\text {add }}, 30.4 ; 95 \%$ CI, $15.6-45.2 ; p<0.01)$. Subsequent multivariable analysis revealed that PRLs $\geq 2$ cases also had higher MSSS ( $\beta_{\text {add }}, 1.1 ; 95 \%$ CI, 0.3-1.9; $p<0.01$ ), whereas MSSS was not affected by DMT or T2 lesion load. On histopathology, both chronic active and smoldering lesions exhibited more severe acute axonal damage at the lesion edge than in the lesion center (edge vs center: $p=$ 0.004 and $p=0.0002$, respectively).

\section{Conclusion}

Chronic white matter inflammation was associated with increased levels of sNfL and disease severity in nonacute MS, suggesting that PRL contribute to clinically relevant, inflammationdriven neurodegeneration.

\author{
Correspondence \\ Dr. Granziera \\ Cristina.granziera@usb.ch
}

\section{RELATED ARTICLE}

\section{Editorial}

Ongoing Axonal Injury in Chronic Active Lesions in Multiple Sclerosis: In Vivo Quantification Using Serum Neurofilament

Page 257

\footnotetext{
*These authors contributed equally to this work.

From the Department of Neurology (P.M., V.v.P.), Cliniques Universitaires Saint-Luc, Université Catholique de Louvain, Brussels, Belgium; Departments of Neurology (P.M., A.M., M.T. C.P., R.D.P.) and Radiology (J.K., M.W., R.G., P.-J.L., R.R., D.L., L.K., C.G.), Lausanne University Hospital and Lausanne University; Departments of Medicine, Clinical Research, and Biomedical Engineering (I.K., M.W., R.G., P.-J.L., R.R., D.L., L.K., C.G.) and Translational Imaging in Neurology (ThINk), Department of Biomedical Engineering Basel (M.W., R.G., R.G., P.J.L., R.R., C.G.), Neurologic Clinic and Policlinic, MS Center and Research Center for Clinical Neuroimmunology and Neuroscience Basel (RC2NB), and Clinical Trial Unit, Department of Clinical Research (S.S., P.B.), University Hospital Basel and University of Basel, Switzerland; Institute of Neuropathology (F.v.d.M., C.S.), University Medical Center Göttingen, Germany; Radiological Physics, Department of Radiology (M.W.), University Hospital Basel; Signal Processing Laboratory (LTS5) (F.L.R., M.B.C.), Ecole Polytechnique Fédérale de Lausanne; CIBM Center for Biomedical Imaging (F.L.R., M.B.C.), Lausanne, Switzerland; Department of Neurology (P.S.), Cedars-Sinai Medical Center, Los Angeles, CA; Translational Neuroradiology Section (P.S., D.S.R., M.A.), National Institute of Neurological Disorders and Stroke, National Institutes of Health, Bethesda; and Department of Neurology (D.S.R., M.A.), Johns Hopkins University, Baltimore, MD.
}

Go to Neurology.org/N for full disclosures. Funding information and disclosures deemed relevant by the authors, if any, are provided at the end of the article. 


\section{Glossary}

$\mathbf{A P P}=$ amyloid precursor protein; $\mathbf{A T}=$ acquisition time; $\mathbf{C I}=$ confidence interval; $\mathbf{D A B}=3,3$ '-diminobenzidine; $\mathbf{D M T}=$ disease-modifying treatment; EDSS = Expanded Disability Status Scale; EPI = echoplanar imaging; FA = flip angle; FLAIR = fluid-attenuated inversion recovery; $\mathbf{G d}=$ gadolinium; $\mathbf{I Q R}=$ interquartile range; $\mathbf{M B P}=$ myelin basic protein; $\mathbf{M H C}=$ major histocompatibility complex; MPRAGE = magnetization-prepared rapid gradient echo; $\mathbf{M S}=$ multiple sclerosis; MSSS = Multiple Sclerosis Severity Scale; NfL = neurofilament light chain; PMS = primary or secondary progressive multiple sclerosis; $\mathbf{P R L}=$ paramagnetic rim lesions; RRMS = relapsing-remitting multiple sclerosis; $\mathbf{s N f L}=$ serum neurofilament light chain; $\mathrm{TE}=$ echo time; $\mathbf{T R}=$ repetition time.

An important unmet clinical and research need for patients with multiple sclerosis (MS) is the understanding of the clinical and pathologic effect of ongoing chronic inflammation within the CNS, which may become the target of future disease-modifying treatment (DMT).

MS is a chronic neuroinflammatory and neurodegenerative disease characterized by focal demyelinated lesions scattered throughout the CNS. ${ }^{1}$ New active MS lesions are characterized by overt inflammation with blood-brain barrier damage and are visible on MRI as focal areas of gadolinium $(\mathrm{Gd})$ enhancement. After the first phase of acute demyelination, a subset of these lesions retains chronic inflammation at the edge (chronic active/smoldering lesions). In the past decade, several MRI-histopathologic validation studies ${ }^{2-10}$ have shown that chronic active/smoldering lesions (although probably not all of them $)^{11}$ can be visualized on susceptibilitybased MRI as non-Gd-enhancing lesions with a paramagnetic $\operatorname{rim}(\mathrm{PRL}){ }^{9,12-15}$

The MRI susceptibility contrast at the lesion rim is mainly related to iron accumulation within activated microglia/ macrophages, ${ }^{2,3,7,16}$ although persistent oxidative stress may also contribute. ${ }^{6,17-19}$ From a clinical point of view, PRL are frequent in both relapsing-remitting and progressive MS and are clinically associated with more aggressive disease. ${ }^{8,14,20,21}$ Whether PRL are associated with increased neuroaxonal damage in living patients with MS is unknown.

Neuropathology studies have shown that iron-rich activated microglia/macrophages and smoldering demyelination can be found at the edge of some chronic MS lesions, ${ }^{7}$ which have been classified as "chronic active" or "smoldering" lesions depending on the amount of myelin phagocytosis observed. $^{22,23}$ Indeed, chronic inflammation and damage to myelin and axons fall on a spectrum, making it sometimes difficult to accurately separate chronic active from smoldering lesions also in histopathologic analyses. Axon loss and ongoing axon damage have been described, respectively, at the center and edge of such lesions, ${ }^{6,10,24-26}$ and there is a correlation between axon injury and the number of chronic active and smoldering lesions in progressive MS cases. ${ }^{20,25,27}$ Taken together, these results suggest that focal chronic inflammation can drive neurodegeneration.
Neuroaxonal damage is considered the substrate of permanent neurologic disability, ${ }^{28}$ and monitoring the levels of neurofilament proteins in the peripheral blood has shown promise as a marker of disease activity and neurodegeneration in MS. $^{29}$ Specifically, previous studies suggest that serum neurofilament light chain (sNfL) levels mirror not only diffuse neuronal loss but also focal inflammatory damage in MS: sNfL levels increase when acute Gd-enhancing lesions are present, correlating with the number of such lesions. ${ }^{30}$ However, whether sNfL levels reflect the presence of chronic white matter inflammation-in the form of PRL-has not been investigated in vivo.

In this study, we assessed whether the presence of PRL in patients with MS, as detected in vivo with susceptibility-based MRI, is associated with an increase in the levels of sNfL. We also aimed to confirm and extend previous knowledge by showing that chronic active and smoldering lesions-the histopathologic correlate of PRL—exhibit substantial axonal loss that colocalizes with chronic inflammatory cells and results in increased neurofilament light chain (NfL) release.

\section{Methods}

\section{Assessment of the Relationship Between PRL and SNfL in Vivo}

\section{Patients}

For all participants, imaging, laboratory, and clinical data were collected between December 2017 and September 2019 in 2 university hospitals (University Hospital Basel and Lausanne University Hospital, Switzerland). Inclusion criteria were adults with a diagnosis of relapsing-remitting MS (RRMS) or primary or secondary progressive MS (PMS) according to the 2017 McDonald MS criteria, ${ }^{31}$ either untreated or on stable DMT for at least 3 months. Cases were excluded for subsequent analysis if they lacked matched imaging, laboratory, and clinical assessments within 6 months; had a clinical relapse or corticosteroid treatment within the 4 months preceding testing; had any Gd-enhancing lesions assessed in clinical MRI performed within 2 months of the study MRI; or had motion-corrupted MRI.

The imaging protocol included high-resolution, susceptibilitybased MRI for PRL assessment (see below). Serum samples 
were collected, stored, and processed for $\mathrm{sNfL}$ analysis at the University Hospital Basel using the NF-Light ${ }^{\circledR}$ assay on single molecule array HDX platform (Quanterix; Billerica). Ageadjusted percentiles of sNfL were calculated in patients with MS in relationship to a database of 259 healthy controls (485 sNfL samples). ${ }^{32}$ Clinical data included Expanded Disability Status Scale (EDSS) ${ }^{33}$ and Multiple Sclerosis Severity Scale (MSSS).$^{34}$ DMT were categorized as follows: (1) untreated; (2) injectable platform drugs with moderate efficacy, including glatiramer acetate and interferon $\beta-1 \mathrm{a} / \mathrm{b}$; (3) oral drugs with mostly high efficacy, including teriflunomide, dimethyl fumarate, and fingolimod; (4) very-high-efficacy drugs, including ocrelizumab, rituximab, natalizumab, and mitoxantrone.

\section{Imaging Acquisition and Analysis}

All participants underwent brain MRI on a 3T Magnetom Skyra or Prisma-fit scanner (Siemens Healthcare) in Lausanne, Switzerland, or a 3T Magnetom Prisma scanner (Siemens Healthcare) in Basel, Switzerland. Imaging at both centers included a high-resolution 3D segmented echoplanar imaging (EPI) sequence providing $\mathrm{T}^{*}$-weighted and phase contrasts (repetition time [TR], $64 \mathrm{~ms}$; echo time [TE], 35 $\mathrm{ms}$; flip angle [FA], $10^{\circ}$; echo-train length, 15; acquisition time [AT], 5 minutes 46 seconds; 288 sagittal slices; $0.65-\mathrm{mm}$ isometric resolution) and a 3D T2-fluid-attenuated inversion recovery (FLAIR) sequence (TR, 5,000 ms; TE, $391 \mathrm{~ms}$; FA, variable; AT, 4 minutes 47 seconds; 176 sagittal slices; 1.0$\mathrm{mm}$ isometric resolution). 3D T1-weighted magnetizationprepared rapid gradient echo (MPRAGE) or MP2RAGE scans were acquired in Lausanne and Basel, respectively.

Phase postprocessing was performed as previously reported, with paramagnetic shifts rendered as hypointense. ${ }^{6,18}$ For each participant, the presence of PRL on unwrapped phase images was independently assessed by 2 raters (P.M. and M.A.). In case of initial disagreement on the presence/ absence of a specific PRL, agreement was reached in a separate session by consensus between the 2 raters. A chronic lesion was rated as a PRL when it showed a hypointense rim and internal isointensity to perilesional white matter on phase images. ${ }^{8,12}$ Automated lesion segmentation was performed using FLAIR and MPRAGE/MP2RAGE images ${ }^{35}$ and manually corrected if needed, yielding total white matter T2hyperintense lesion volume (T2 lesion load). Brain volumes (gray matter volume + white matter volume/total intracranial volume) were computed using FreeSurfer (surfer.nmr.mgh. harvard.edu) after lesion filling on MPRAGE/MP2RAGE images.

\section{Statistical Analysis}

Cases were initially categorized in 3 groups based on previous evidence from the literature according to the number of PRLs $(0,1-3, \geq 4)^{8,15}$; due to the statistical distribution of the data in this particular study, we implemented a simpler cutoff of PRL $0-1$ and $\geq 2$. The interrater reliability for PRL groups was computed using Cohen $\kappa$. Baseline differences (demographic and clinical) between PRL groups were assessed in a univariable analysis using $t$ test, Mann-Whitney $U$ test, or $\chi^{2}$ test, as appropriate. The association between clinical and MRI measures and PRL ( $0-1$ and $\geq 2$; dependent variable) was assessed in a multivariable logistic model using MRI lesion load, disease duration, MS subtype, and DMT as covariates (estimates $\beta_{\mathrm{OR}}$ are back-transformed, indicating the odds ratio for $\geq 2$ vs $0-1$ PRL). The number of PRLs was assessed in a negative binomial model using the same independent variables (estimates $\beta_{\text {IRR }}$ are back-transformed, indicating the PRL incidence rate ratio associated with unit increase in the respective covariate). To achieve an age-independent estimation of sNfL, levels were described as age-dependent percentiles derived from healthy controls, as previously described. $^{30}$

The association between PRL categories and sNfL percentiles (dependent variable) was tested in a multivariable linear model using EDSS, MS subtype, MRI lesion load, and DMT as covariates (estimates $\beta_{\text {add }}$ indicate the estimated increase in sNfL percentile). To compare our results to 2 recent studies, ${ }^{8,15}$ we repeated the same analysis after grouping MS cases according to a different PRL number cutoff $(0,1-3$, and $\geq 4$ ). The association between PRL groups and MSSS (dependent variable) was assessed in a multivariable linear model using PRL number, MS subtype, MRI lesion load, and DMT as covariates (estimates $\beta_{\text {add }}$ indicate the number of points MSSS is estimated to increase).

To exclude any possible influence of the different $3 \mathrm{~T}$ scanners on the results, we repeated all analyses adding "scanner type" as covariate.

\section{Standard Protocol Approvals, Registrations, and Patient Consents}

For this study, we received approval from the local ethical standards committee on human experimentation and written informed consent was obtained from all patients participating in the study (consent for research). The Consolidated Standards of Reporting Trials chart is provided in eFigure 1 (doi. org/10.5061/dryad.pk0p2ngn3).

\section{Assessment of the Presence of Acute Axonal Damage in Histopathologic Correlates of PRL (Chronic Active/Smoldering Lesions)}

\section{Neuropathologic Analysis}

Formalin-fixed, paraffin-embedded brain tissue was randomly selected from archival autopsy MS cases that had been collected at the Institute of Neuropathology at the University Medical Center Göttingen.

Neuropathologic evaluation of lesions at different histopathologic stages ${ }^{22,23}$ was performed to assess the extent of acute axonal damage in relation to macrophage infiltration/ microglia activation and ongoing demyelination in both the lesion core and edge. Paraffin-embedded 2- to 3- $\mu \mathrm{m}$-thick 
tissue sections were deparaffinized; stained with hematoxylin \& eosin, Luxol fast blue/periodic acid-Schiff, myelin, and Bielschowsky silver impregnation method (axons); and immunohistochemistry was performed according to standard procedures. Primary antibodies were diluted in blocking buffer and incubated overnight at $4^{\circ} \mathrm{C}$. Antibody binding was visualized using biotinylated secondary antibodies (GE Healthcare, Jackson ImmunoResearch, and DCS Innovative Diagnostic Systems), peroxidase-conjugated avidin, and 3,3' diminobenzidine (DAB; Sigma-Aldrich). Double-labeling immunohistochemistry was performed combining $\mathrm{DAB}$ and Fast Blue using alkaline phosphatase-conjugated secondary antibody (Dako). The following primary antibodies were used: mouse anti-CD68-macrophage/activated microglia antibody (clone KiM1P, 1:50, gift of Prof. Dr. Heinz-Joachim Radzun, Göttingen), mouse anti- $\beta$-amyloid precursor protein (APP; Merck Millipore, MAB348, clone 22C11, 1:2000), and rabbit anti-myelin basic protein (MBP; Dako, A0623, 1:2000). Quantitative analysis of APP-positive $(\mathrm{APP}+)$ axonal spheroids (acutely injured axons), CD68-positive macrophages/activated microglia, and MBP-containing phagocytes was performed using a $10 \times 10$ ocular morphometric grid $(400 \times$ magnification; Olympus). The results were expressed as cells $/ \mathrm{mm}^{2}$

\section{MRI Pathology}

One MS brain was imaged on a 3T Prisma MRI system using a 20-channel head-and-neck coil and a dome-shaped brain container filled with perfluoropolyether. The brain was fixed in $4 \%$ formalin within 24 hours from the time of death and for 4 months before the MRI. Postmortem unwrapped phase images were obtained from a 3D-EPI acquisition (330 $\mu \mathrm{m}$ isometric, TR $65 \mathrm{~ms}$, TE $35 \mathrm{~ms}$, echo train length 13, bandwidth $394 \mathrm{~Hz} /$ pixel). The matching between MRI and histopathology was achieved through a personalized 3D-printed cutting box. $^{36}$ Additional manual registration between the digitized brain slab surfaces and the corresponding MRI slices was performed to further refine the match between histopathology and MRI. Immunohistochemistry for myelin, microglia/macrophages, and acute axonal injury was obtained using anti-MBP, major histocompatibility complex (MHC) class II (clone CR3/43) and anti- $\beta$-APP (Chemicron) antibodies; ferrous iron $\left(\mathrm{Fe}^{2+}\right)$ was visualized using Turnbull staining as previously described. ${ }^{3,22}$

\section{Statistical Analysis}

Differences in APP+ spheroid densities between the center and the edge of lesions available for neuropathologic analysis were assessed using the Mann-Whitney $U$ test. Differences in CD68+ phagocyte density and MBP+ phagocyte density between early active, chronic active, smoldering, and chronic inactive lesions were assessed using 1-way analysis of variance and Kruskal-Wallis test with Dunn multiple comparison test. To assess a possible correlation between APP + spheroids and CD68+ activated microglia/macrophages at the lesion edge, nonparametric Spearman correlation was used. Statistical analysis was performed using $\mathrm{R}$ version 3.6 .3 (2020-02-29) and Prism version 6.0 (GraphPad).

\section{Data Availability}

Anonymized data will be shared by reasonable request from the principal investigator.

\section{Results}

\section{Assessment of the Relationship Between PRL and SNfL in Vivo}

\section{Participant Characteristics}

Of 137 consecutively screened adults with MS, 118 (86\%) were included in this study (10 were excluded because of motion artifacts and 9 because of the presence of $\mathrm{Gd}$ -

Figure 1 Representative MRI of Paramagnetic Rim Lesion (PRL) $0-1$ and PRLs $\geq 2$ in Multiple Sclerosis (MS) and Respective Serum Neurofilament Light Chain (sNfL) Percentiles
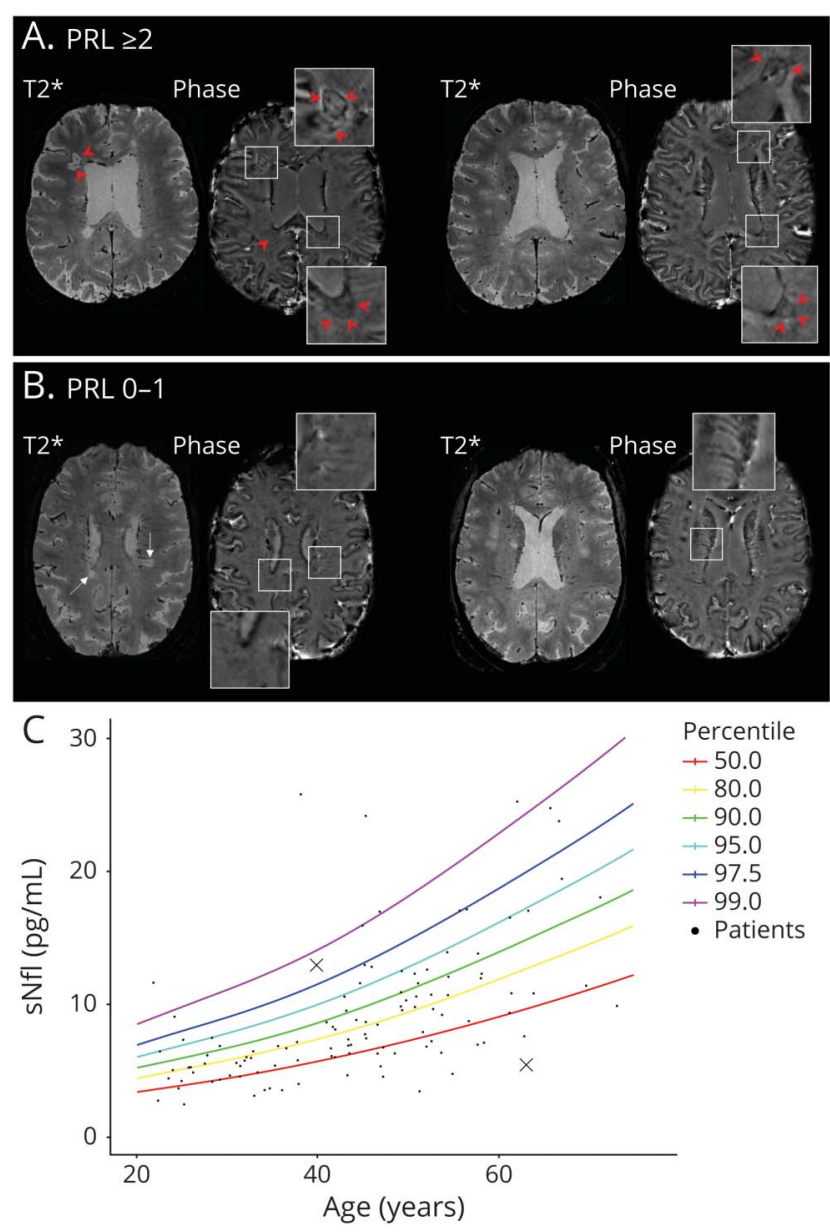

Axial 3T T2*-weighted magnitude and phase MRI of (A) a patient with PRLs $\geq 2$ (relapsing-remitting MS, 40 years old, male; 12 PRLs) with high sNfL (98th percentile) and (B) a patient with PRL 0-1 (secondary progressive MS, 64 years old, male; 0 PRLs) with low sNfL (3rd percentile). PRLs are visible in A (arrowheads) but not B (arrows). Insets show magnified views. C, Age-adjusted sNfL percentiles for patients with PRL 0-1 or PRLs $\geq 2$ ( $A, B$, crosses) and for the 118 patients with MS included in the study (dots). Colored lines represent the percentile levels. 
enhancing lesions); 86 (73\%) had RRMS and 32 (27\%) had PMS.

Overall, 70/118 participants (59\%) had $\geq 1$ PRL, 43 (36\%) had $\geq 2$ PRL, and 30 (25\%) had $\geq 4$ PRL. Among patients with PMS, 22/32 (69\%) had $\geq 1$ PRL, 18/32 (56\%) had $\geq 2$ PRL, and 13/32 (41\%) had $\geq 4$ PRL; among patients with RRMS, 48/86 (56\%) had $\geq 1$ PRL, 29/86 (34\%) had $\geq 2$ PRL, and $17 / 86(20 \%)$ had $\geq 4$ PRL. Cohen $\kappa$ for the interrater reliability of PRL assessment was 0.83 . The median time lapse between MRI acquisition and clinical-laboratory assessment was 15 days (interquartile range [IQR], 1.5-36; range, $0-174)$. Only 14 of 118 patients (12\%) had a blood sample performed more than 60 days from the MRI.

Based on our previous observations, ${ }^{8,15}$ cases were initially categorized in 3 groups according to the number of PRLs (0, $1-3$, and $\geq 4$; eTable 1, doi.org/10.5061/dryad.pk0p2ngn3). However, due to the distribution of the cohort data in this study, we implemented a simpler cutoff of PRL $0-1$ and $\geq 2$. Thus, hereafter, cases without PRL or with only 1 PRL are

Table 1 Clinical, Laboratory, and MRI Demographics

\begin{tabular}{|c|c|c|c|}
\hline & PRL $0-1$ cases & PRL $\geq 2$ cases & $p$ Value \\
\hline Patients & 75 & 43 & \\
\hline MS subtype & & & 0.43 \\
\hline RRMS & $57(76)$ & $29(67)$ & \\
\hline PMS & $18(24)$ & $14(33)$ & \\
\hline Median age, y & $45(36-53)$ & $45(32-54)$ & 0.75 \\
\hline \multicolumn{4}{|l|}{ Clinical data } \\
\hline \multicolumn{3}{|l|}{ Treatment } & \multirow[t]{4}{*}{0.34} \\
\hline Untreated/platform & $19(25)$ & $12(28)$ & \\
\hline Oral & $27(36)$ & $10(23)$ & \\
\hline Very-high-efficacy & $29(39)$ & $21(49)$ & \\
\hline Disease duration, $y$ & $9(5-19)$ & $11(5-15)$ & 0.90 \\
\hline EDSS score & $2.0(1.5-4.0)$ & $3.0(2.0-5.5)$ & 0.01 \\
\hline MSSS score & $2.4(1.5-4.6)$ & $4.3(3.1-6.2)$ & 0.003 \\
\hline \multicolumn{4}{|l|}{ MRI data } \\
\hline Normalized brain volume & $0.62(0.58-0.74)$ & $0.61(0.56-0.77)$ & 0.53 \\
\hline T2 lesion load, mL & $2.2(0.6-6.4)$ & $7.8(4.0-17.9)$ & $<0.001$ \\
\hline \multicolumn{4}{|l|}{ Laboratory data } \\
\hline sNfL percentile & $68(41-84)$ & 91 (77-97) & $<0.001$ \\
\hline
\end{tabular}

Abbreviations: EDSS = Expanded Disability Status Scale; MS = multiple sclerosis; MSSS = Multiple Sclerosis Severity Score; PMS = primary or secondary progressive multiple sclerosis; $\mathrm{PRL}=$ paramagnetic rim lesions; RRMS = relapsing-remitting multiple sclerosis; sNfL = serum neurofilament light chain.

Normalized brain volume = gray matter volume + white matter volume/tota intracranial volume. Values are $\mathrm{n}(\%)$ or median (25th-75th percentile). termed PRL 0-1 $(\mathrm{n}=75,64 \%)$, whereas cases with $\geq 2(\mathrm{n}=$ $43,35 \%)$. Figure 1 shows representative MRI of PRL $0-1$ and PRLs $\geq 2$ MS cases and their respective sNfL percentiles; Yable 1 lists clinical, laboratory, and MRI characteristics.

Of the 118 patients included in the study, 28 (24\%) were untreated (14 RRMS and 14 PMS). The percentage of patients receiving DMT (including very-high-efficacy treatments) was similar between PRL $0-1$ and PRLs $\geq 2$ cases. PRLs $\geq 2$ cases were more disabled (median EDSS score 3, IQR 3.5) than PRL 0-1 cases (median 2, IQR 2.5) $(p=0.01)$, and this was true also when scaling EDSS by disease duration (median MSSS score, 4.3 [IQR 3.1] vs 2.4 [IQR 3.16], respectively; $p=0.003) .{ }^{34}$

T2 lesion load was higher in PRLs $\geq 2$ cases $(p<0.001)$. Normalized brain volume (cortical plus white matter volumes/total intracranial volume) did not significantly differ between PRL $0-1$ and PRLs $\geq 2$ cases. Similarly, we did not observe betweengroup differences for volumes of cortex, white matter, thalamus, or basal ganglia (putamen, pallidus, and caudate) (eFigure 2, doi.org/10.5061/dryad.pk0p2ngn3). Finally, median sNfL percentile was higher in PRLs $\geq 2$ (median 91, IQR 20) than PRL 0-1 (median 68, IQR 43) cases $(p<0.001)$. Segregation of cases according to both PRL status (PRL $0-1$ and PRLs $\geq 2$ ) and different sNfL percentile thresholds (50th, 80th, and 90th) is shown in eTable 2, doi.org/10.5061/dryad.pk0p2ngn3.

\section{Association between PRL and sNfL}

PRLs $\geq 2$ cases had on average 16 percentile-point higher sNfL ( $\beta_{\text {add }}, 16.3 ; 95 \%$ confidence interval $[\mathrm{CI}], 4.6-28.0 ; p<0.01$ ) compared to PRL $0-1$ cases. No other covariate, including MS subtype (RRMS vs PMS), DMT, EDSS, and T2 lesion load, showed an independent effect on sNfL levels (Figure 2A). Furthermore, cases with 1-3 PRLs $(n=40)$ and $\geq 4$ PRLs ( $=$ $30)$ had 15 and 30 percentile-point higher sNfL levels than cases with 0-1 PRL ( $\beta_{\text {add }}, 14.8 ; 95 \%$ CI, 3.2-26.3; $p=0.01$ and $\beta_{\text {add }}$ 30.4; 95\% CI, 15.6-45.2; $p<0.01$, respectively). Again, no other covariate showed an effect on sNfL levels (Figure 2B).

Moreover, there was no association between normalized brain volume and sNfL in the model that included $\geq 2$ PRLs as independent variable. Also, there was no evidence that the difference in scanners influenced the association between brain volume and NfL percentiles (eTable 3,doi.org/10. 5061/dryad.pk0p2ngn3).

\section{Association Between PRL and Clinical MRI Measures}

Higher T2 lesion load (per $\mathrm{mL}$ unit) and shorter disease duration (per year unit) were respectively associated with $21 \%$ and $7 \%$ higher odds of having PRLs $\geq 2$ ( $\beta_{\mathrm{OR}}, 1.21 ; 95 \%$ CI, $1.12-1.33 ; p<0.01$ and $\beta_{\mathrm{OR}}, 1.07 ; 95 \% \mathrm{CI}, 1.01-1.14 ; p=$ 0.02 , respectively).

MS subtype (RRMS vs PMS; $\beta_{\mathrm{OR}}$ 0.99; 95\% CI, 0.27-3.74; $p$ $=0.99$ ) and current DMT, including oral (vs. platform, $\beta_{\mathrm{OR}}$ 
Figure 2 Paramagnetic Rim Lesions (PRLs) Strongly and Uniquely Predict Serum Neurofilament Light (sNfL) Levels

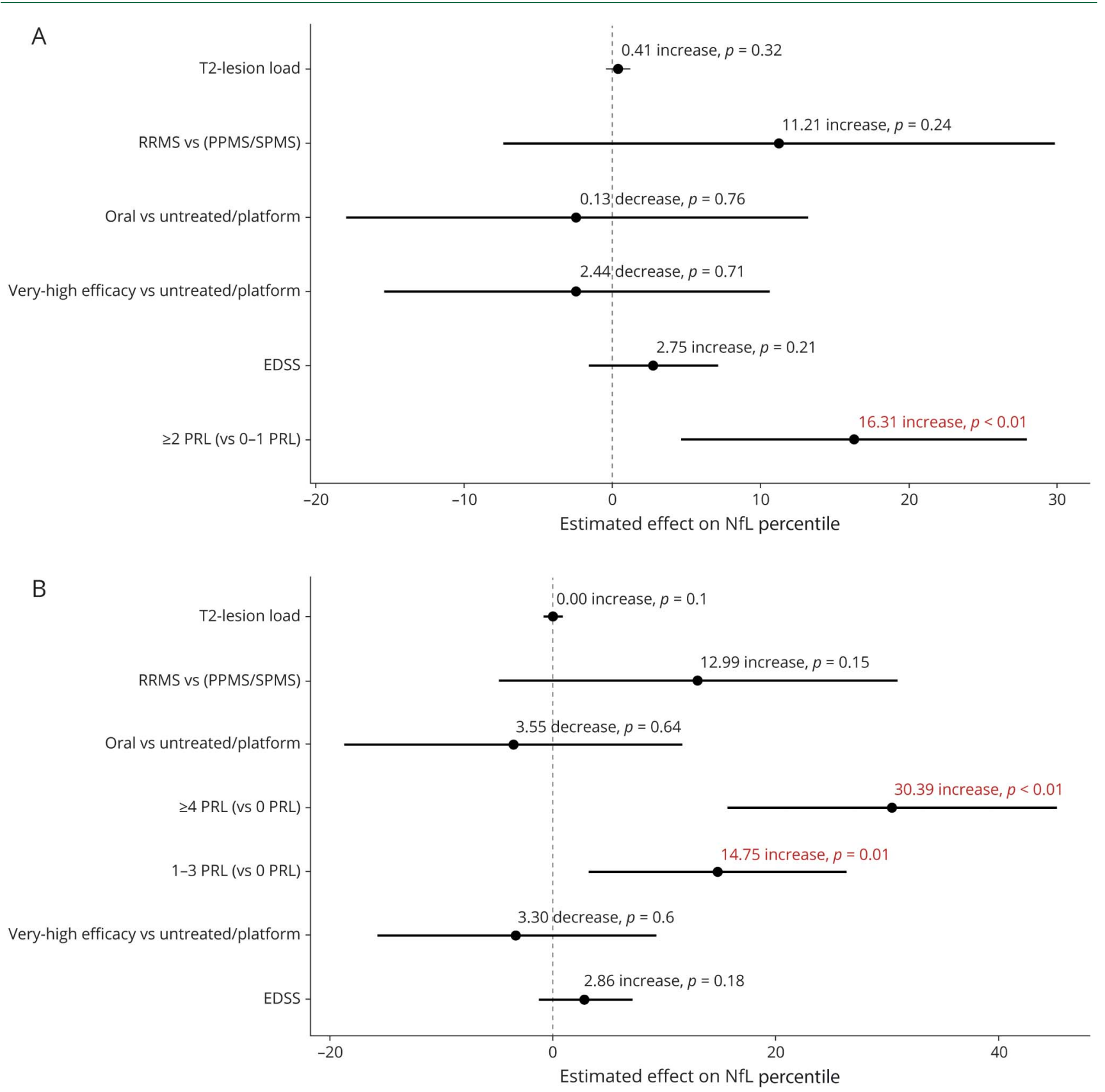

(A) Estimated effects of T2 lesion load, multiple sclerosis subtype, Expanded Disability Status Scale (EDSS), oral and very-high-efficacy disease-modifying treatment (DMT), and the presence of $\geq 2$ PRLs, as compared to 0-1 PRL, on age-corrected sNfL percentile levels. (B) The same model is shown using a 3-group PRL categorization (0, 1-3, and $\geq 4 \mathrm{PRL}$ ). Platform DMTs are glatiramer acetate and interferon $\beta-1 \mathrm{a} / \mathrm{b}$; oral DMT, teriflunomide, dimethyl fumarate, and fingolimod; and very-high-efficacy DMT: ocrelizumab, rituximab, natalizumab, or mitoxantrone. NfL = neurofilament light chain; ns = nonsignificant $(p \geq 0.05)$; PPMS = primary progressive multiple sclerosis; RRMS = relapsing-remitting multiple sclerosis; SPMS = secondary progressive multiple sclerosis.

0.78; 95\% CI, 0.21-3.05; $p=0.72$ ) and very-high-efficacy (vs. platform, $\beta_{\mathrm{OR}}$ 0.93; 95\% CI, 0.28-3.16; $p=0.91$ ), were not associated PRLs $\geq 2$ status.

Results were similar when using the number of PRLs per case as the dependent variable: only higher T2 lesion load ( $\beta_{\text {IRR }}$ $1.13 / \mathrm{mL}$; 95\% CI, 1.09-1.18; $p<0.01$ ) and shorter disease duration ( $\beta_{\text {IRR }} 1.05 /$ year; 95\% CI, $1.01-1.08$; $p<0.01$ ) were associated with the number of PRLs.

\section{Association Between PRLs and Disease Severity}

Not surprisingly, MSSS was higher by 2.7 points in PMS vs RRMS cases ( $\beta_{\text {add }}, 2.7$; 95\% CI, 1.4-3.6; $p<0.01$ ). In PRLs $\geq 2$ cases, MSSS was on average 1.1 points higher than in PRL $0-1$ cases $\left(\beta_{\text {add }} 1.1 ; 95 \% \mathrm{CI}, 0.3-1.9 ; p<0.01\right)$. No other covariate, including current DMT (oral: $\beta_{\text {add }},-0.8 ; 95 \% \mathrm{CI},-1.8$ to $0.3 ; p=0.14$; very-high-efficacy: $\beta_{\text {add }}, 0.1 ; 95 \% \mathrm{CI},-0.7$ to $1.0 ; p=0.75)$, and T2 lesion load ( $\beta_{\text {add }},-0.02 ; 95 \% \mathrm{CI},-0.07$ to $0.04 ; p=0.54$ ), was associated with MS severity. 

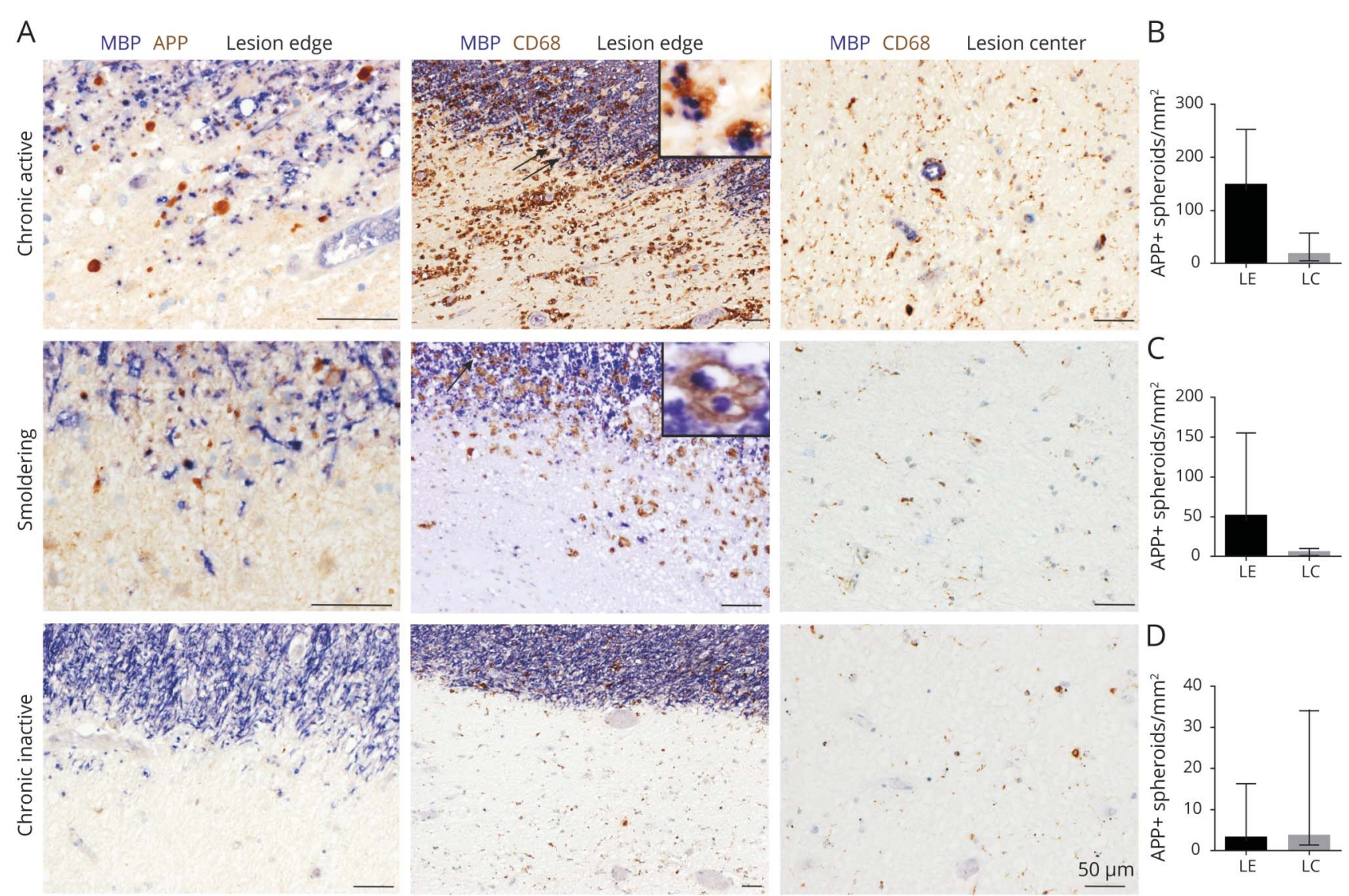

E

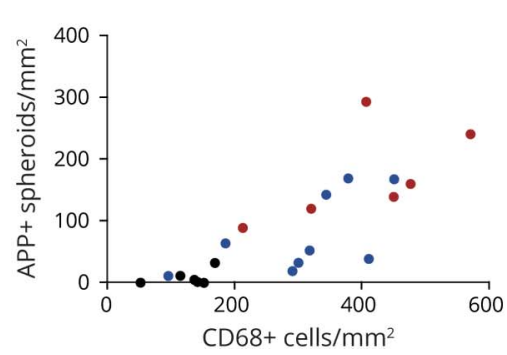

- Chronic active

- Smoldering

- Chronic inactive

(A) Double immunohistochemistry for myelin basic protein (MBP) (blue) with human $\beta$-amyloid precursor protein (APP) (brown) or CD68 (clone KiM1P) at the lesion edge and center of chronic active, smoldering, and chronic inactive lesions. Insets highlight CD68+ phagocytes containing MBP+ particles. (B-D) Quantification of APP+ spheroids at the lesion edge $(\mathrm{LE})$ and center $(\mathrm{LC})$ of chronic active lesions $(\mathrm{n}=6$; Mann-Whitney $U$ test, $p=0.004)$, smoldering lesions $(\mathrm{n}=$ 9; Mann-Whitney $U$ test, $p=0.0002)$, and chronic inactive lesions ( $\mathrm{n}=6$; Mann-Whitney $U$ test, $p=0.46)$. (E) Correlation of the density of APP + spheroids with the density of CD68+ macrophages/activated microglia at the lesion border of chronic active/smoldering and chronic inactive lesions ( $\mathrm{n}=21 ; r=0.8648 ; p<$ 0.0001; nonparametric Spearman correlation). CD68 = CD68-macrophage/activated microglia antibody (clone KiM1P).

\section{Assessment of the Presence of Acute Axonal Damage in Histopathologic Correlates of PRL (Chronic Active/Smoldering Lesions)}

From an additional group of 20 autopsy MS cases (19 PMS/1 RRMS, 8 women/ 12 men, mean age 52 years, range 28-67), we studied the following MS lesions classified according to their pathologic stage $e^{22,23}$ : early active $(n=4)$, chronic active $(\mathrm{n}=6)$, smoldering $(\mathrm{n}=9)$, and chronic inactive $(\mathrm{n}=6)$. Quantification of CD68+ activated microglia/macrophages and CD68+ phagocytes containing MBP + particles (eFigure 3, doi.org/10.5061/dryad.pk0p2ngn3) showed that chronic active and smoldering lesions fall on a spectrum of inflammatory demyelinating activity at the lesion edge and a hypocellular core. $^{22,23}$

Acutely injured axons $(\mathrm{APP}+)$ were rarely observed both in the center and at the edge of chronic inactive lesions. On the other hand, in chronic active/smoldering lesions, APP+ injured axons colocalized with the active edge of CD68+ macrophages/activated microglia, some of which contained MBP (Figure 3A). Quantitative analysis of acutely injured axons showed (1) in chronic active/smoldering lesions (Figure 3, B and C), the median number of APP+ spheroids per $\mathrm{mm}^{2}$ was higher at the lesion edge (149.3 [IQR 104.9] 

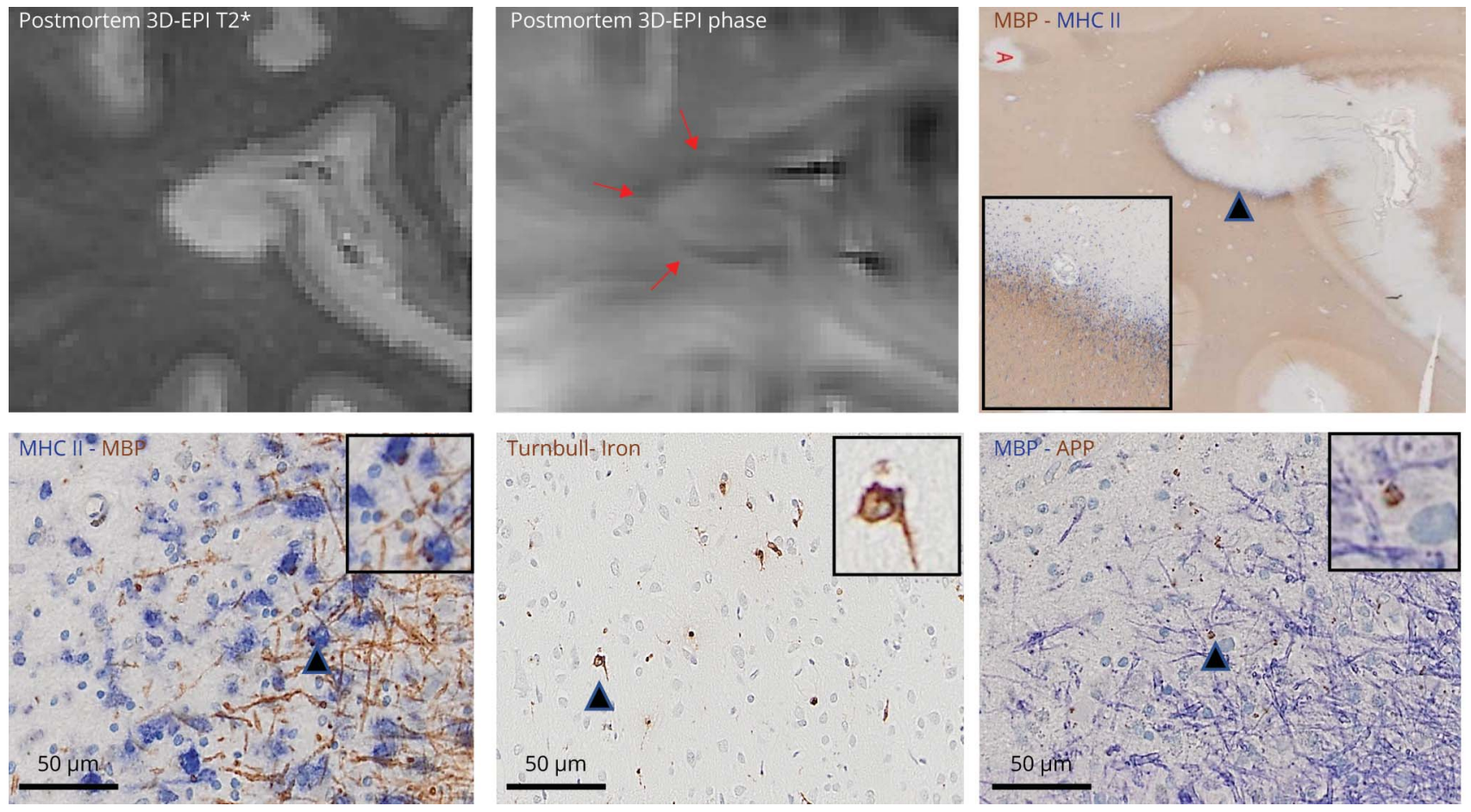

Matched MRI-histopathologic assessment of 1 representative chronic active lesion in the cerebral white matter of a 59-year-old patient with PMS (disease duration 24 years, Expanded Disability Status Scale $=8$ ). The paramagnetic rim visible on the postmortem 3D-echoplanar imaging (EPI) phase (red arrows) corresponds on histopathology to an actively inflammatory demyelinating edge of major histocompatibility complex class II clone CR3/43 (MHC II)+ macrophages/microglia containing myelin basic protein (MBP)+ myelin degradation products (MBP-MHC II) and iron (Turnbull-iron [3,3' diaminobenzidinetetrahydrochloride-enhanced Turnbull staining]). Amyloid precursor protein (APP)+ acutely injured axons are found at the demyelinated lesion edge (MBPAPP).

and 52.3 [IQR 129.6]) than at the lesion center (19.6 [IQR 52.0] and 6.4 [IQR 8.3]; $p=0.004$ and $p=0.0002)$; and (2) in chronic inactive lesions (Figure 3D), APP+ spheroids were only rarely found both at the lesion edge and in the lesion center (median 3.3 [IQR 16.4] and 3.8 [IQR 32.8]; $p$ $=0.46$ ). The density of APP+ axonal spheroids positively correlated with the density of CD68 macrophages/ activated microglia at the edge of chronic active/ smoldering and chronic inactive lesions $(r=0.86$; $p<$ 0.0001; Figure 3E).

We acquired postmortem 3D-EPI images in a 59-year-old man with PMS (disease duration 24 years, EDSS $=8$ prior to death) and performed a matched MRI-histopathologic assessment of 1 exemplary chronic active lesion. This chronic active lesion, which featured a paramagnetic rim on 3D-EPI phase MRI, showed ongoing inflammatory demyelination with iron accumulation as well as acute axonal damage at the lesion edge (Figure 4).

\section{Discussion}

Our multicenter study provides clear evidence of a relationship between the presence of $\geq 2$ PRLs and higher levels of sNfL in patients with MS (both RRMS and PMS) without acute disease activity, showing that PRLs are associated with neuroaxonal degeneration that can be detected in vivo. Furthermore, our postmortem evaluation shows that the histologic correlates of PRL-chronic active and smoldering lesions-exhibit pronounced axon damage at the lesion edge, which colocalizes with chronic inflammatory cells.

In our in vivo study, the association between PRL and sNfL was independent of other factors previously shown to influence sNfL, such as age, T2 lesion load, and DMT (including veryhigh-efficacy DMT). ${ }^{30,37,38}$ This somewhat surprising result may be partially explained by the fact that we studied a cohort with neither clinical nor radiologic inflammatory activity, whereas many other studies included both active and nonactive patients. In addition, it is possible that the effects of those clinical factors may partially be mediated through PRL.

Our data show that most patients with PRLs $\geq 2$ (72\%) had sNfL levels above the 80th percentile, a frankly pathologic threshold according to previous studies. ${ }^{30}$ Thus, our findings are relevant not only at the group level but also at the patient level (eTable 2, doi.org/10.5061/dryad.pk0p2ngn3). Discrepancies between sNfL levels and the presence/absence of PRL, observed in a minority of patients, require further investigation in larger cohorts and suggest that other factors may also play a role. 
The increase in sNfL that we described typically corresponds to only a handful of additional PRLs in each case, indicating that even the limited amount of ongoing axon damage at the edge of chronic active/smoldering lesions-substantially less than what occurs in active lesions-can be detected in the serum. This profound focal damage also results in MRIdetectable expansion of some PRLs over a period of a few years, such that these lesions are both larger and more T1hypointense on MRI than other MS lesions. ${ }^{6-8,10,24-26}$

In our cohort of nonactive MS, there was no difference in brain volume between PRLs $\geq 2$ and PRL $0-1$ cases. This suggests that cross-sectional brain volume measurementsunlike PRL detection-do not provide a reliable snapshot of ongoing neuroaxonal destruction at the time of MRI. ${ }^{39}$ Furthermore, despite the presence of a higher T2 lesion load in PRLs $\geq 2$ compared to PRL 0-1 patients, the number and volume of $\mathrm{T} 2$ lesions were not significantly related to sNfL levels, signifying that it is fundamental to identify the subtype of lesions that drives relentless neuroaxonal degeneration outside clinical and radiologic relapses.

In agreement with recent evidence, ${ }^{8,9,15}$ we found that PRLs are frequent in both RRMS and PMS, with more than onethird of the patients (36\%) harboring at least 2 PRLs. We also found an inverse association between PRLs and disease duration, supporting the idea that smoldering inflammation/ demyelination at early disease stages might trigger clinical progression, but also that it might partially decline at the later stages of the disease. In addition, these data suggest that clinical estimates of disease duration are not reliable, especially in patients with insidious and progressive disease course.

Our work also extends previous findings ${ }^{8,15,40}$ by showing that the reported association between PRLs and clinical disability also holds in the absence of clinical or radiologic signs of acute inflammation. Indeed, in our cohort, the association between PRLs and MSSS was stronger than, and independent from, factors known to influence clinical outcomes in MS, such as T2 lesion load and very-high-efficacy DMT.

The histopathologic analysis performed in this work provides additional evidence that the histopathologic correlates of PRL-chronic active and smoldering lesions-exhibit high numbers of acutely injured axons (APP+ spheroids) at the lesion edge and lesion core, which lead to the release of axonal cytoskeleton proteins (including NfL) in CSF and blood. Here, acute axon injury and degeneration, leading to the release of neurofilaments (axonal cytoskeleton proteins) in the CSF and blood, was assessed using APP immunostaining, since APP transiently accumulates in acutely transected axon end-bulbs, ${ }^{25,27,41}$ whereas neurofilament immunostaining reflects only past axon depletion. ${ }^{42}$ In line with previous reports, ${ }^{6,24-26,43}$ we showed that acute axonal injury and transection occur along with the inflammatory activity of activated macrophages and microglia in both chronic active and smoldering lesions, despite variable ongoing demyelination.

This study has some limitations. First, although serum samples were collected as close as possible to the MRI scan, in some cases $(14 / 118[12 \%])$ this time frame exceeded several months. While we cannot exclude that the chronic inflammatory status of such patients may have changed during this time gap, this is not likely considering the temporal persistence of PRLs, which have been shown to last for at least several years. ${ }^{7,10}$ Second, larger cohorts of participants are required to achieve adequate statistical power to consider the actual number of PRLs per case (rather than dichotomizing or trichotomizing that number) in a multivariable analysis. Also, studies focusing on specific patient subgroups (e.g., early- vs late-stage RRMS) will have to be performed in the future. Regarding the effect of treatment, future longitudinal studies are required to investigate the differential effect (if any) of available DMT on these biomarkers.

We provide in vivo MRI and laboratory evidence that chronically inflamed lesions on MRI (PRLs) are associated with elevated sNfL in people with MS. The association between PRLs and sNfL was strong and independent from other factors known to influence sNfL levels. Hence, we postulate that PRLs may be a substantial driver of neuroaxonal damage and clinical disability in patients without clinical or radiologic signs of acute inflammation. This is a concept of key importance and further supports the role of PRLs as a biomarker for patient stratification and treatment outcome in future clinical trials.

\section{Acknowledgment}

Franziska van der Meer died on November 9, 2020. The authors thank the study participants; the neuroimmunology clinics at each center for recruiting and evaluating the patients and for coordinating the scans; Tobias Kober (Advanced Clinical Imaging Technology, Siemens Healthineers, Lausanne) and Jean-Baptiste Ledoux (TRM coordinator, Service de "Radiodiagnostic et Radiologie Interventionnelle," Lausanne University Hospital) for assistance with 3T MRI scan acquisition; the medical physics department at Basel University Hospital for hosting the study; and Marguerite Limberg for helping with patient enrollment at Basel University Hospital.

\section{Study Funding}

This study was partially supported by the Intramural Research Program of NINDS, NIH; European Union's Horizon 2020 research and innovation program under the Marie Sklodowska-Curie project TRABIT (agreement 765148); and the CIBM Center for Biomedical Imaging.

\section{Disclosure}

Jens Kuhles' work is supported by the Swiss National Science Foundation (320030_189140/1). Cristina Granziera is 
supported by the Swiss National Science Foundation (SNSF) grant PP00P3_176984, the Stiftung zur Förderung der Gastroenterologischen und All-Gemeinen Klinischen Forschung, and the EUROSTAR E!113682 HORIZON2020. Martina Absinta is supported by the Conrad N. Hilton Foundation (grant 17313). The other authors report no funding or support directly relevant to the manuscript. Go to Neurology.org/ $\mathrm{N}$ for full disclosures.

\section{Publication History}

Received by Neurology November 13, 2020. Accepted in final form May 5, 2021.

Appendix Authors

\begin{tabular}{|c|c|c|}
\hline Name & Location & Contribution \\
\hline $\begin{array}{l}\text { Pietro Maggi, } \\
\text { MD, PhD }\end{array}$ & $\begin{array}{l}\text { Université } \\
\text { Catholique de } \\
\text { Louvain }\end{array}$ & $\begin{array}{l}\text { Designed and conceptualized study; } \\
\text { analyzed the data; drafted the } \\
\text { manuscript for intellectual content }\end{array}$ \\
\hline $\begin{array}{l}\text { Jens Kuhle, MD, } \\
\text { PhD }\end{array}$ & $\begin{array}{l}\text { University of } \\
\text { Basel }\end{array}$ & $\begin{array}{l}\text { Designed and conceptualized study; } \\
\text { analyzed the data; drafted the } \\
\text { manuscript for intellectual content }\end{array}$ \\
\hline $\begin{array}{l}\text { Sabine } \\
\text { Schaedelin, } \\
\text { MSc }\end{array}$ & $\begin{array}{l}\text { University of } \\
\text { Basel }\end{array}$ & $\begin{array}{l}\text { Analyzed, interpreted the data; } \\
\text { revised the manuscript for intellectual } \\
\text { content }\end{array}$ \\
\hline $\begin{array}{l}\text { Franziska van } \\
\text { der Meer, PhD }\end{array}$ & $\begin{array}{l}\text { University of } \\
\text { Göttingen }\end{array}$ & $\begin{array}{l}\text { Analyzed, interpreted the data; } \\
\text { revised the manuscript for intellectual } \\
\text { content }\end{array}$ \\
\hline $\begin{array}{l}\text { Matthias } \\
\text { Weigel, PhD }\end{array}$ & $\begin{array}{l}\text { University of } \\
\text { Basel }\end{array}$ & $\begin{array}{l}\text { Major role in the acquisition of data; } \\
\text { revised the manuscript for intellectual } \\
\text { content }\end{array}$ \\
\hline $\begin{array}{l}\text { Riccardo } \\
\text { Galbusera, MD }\end{array}$ & $\begin{array}{l}\text { University of } \\
\text { Basel }\end{array}$ & $\begin{array}{l}\text { Analyzed, interpreted the data; } \\
\text { revised the manuscript for intellectual } \\
\text { content }\end{array}$ \\
\hline $\begin{array}{l}\text { Amandine } \\
\text { Matthias, PhD }\end{array}$ & $\begin{array}{l}\text { University of } \\
\text { Lausanne }\end{array}$ & $\begin{array}{l}\text { Interpreted the data; revised the } \\
\text { manuscript for intellectual content }\end{array}$ \\
\hline Po-Jui Lu, MSc & $\begin{array}{l}\text { University of } \\
\text { Basel }\end{array}$ & $\begin{array}{l}\text { Major role in the acquisition of data; } \\
\text { revised the manuscript for intellectual } \\
\text { content }\end{array}$ \\
\hline $\begin{array}{l}\text { Reza } \\
\text { Rahmanzadeh, } \\
\text { MD }\end{array}$ & $\begin{array}{l}\text { University of } \\
\text { Basel }\end{array}$ & $\begin{array}{l}\text { Major role in the acquisition of data; } \\
\text { revised the manuscript for intellectual } \\
\text { content }\end{array}$ \\
\hline $\begin{array}{l}\text { Pascal Benkert, } \\
\text { PhD }\end{array}$ & $\begin{array}{l}\text { University of } \\
\text { Basel }\end{array}$ & $\begin{array}{l}\text { Analyzed, interpreted the data; } \\
\text { revised the manuscript for intellectual } \\
\text { content }\end{array}$ \\
\hline $\begin{array}{l}\text { Francesco La } \\
\text { Rosa, MSc }\end{array}$ & $\begin{array}{l}\text { University of } \\
\text { Lausanne }\end{array}$ & $\begin{array}{l}\text { Analyzed, interpreted the data; } \\
\text { revised the manuscript for intellectual } \\
\text { content }\end{array}$ \\
\hline $\begin{array}{l}\text { Merixtell Bach } \\
\text { Cuadra, PhD }\end{array}$ & $\begin{array}{l}\text { University of } \\
\text { Lausanne }\end{array}$ & $\begin{array}{l}\text { Interpreted the data; revised the } \\
\text { manuscript for intellectual content }\end{array}$ \\
\hline Pascal Sati, PhD & $\begin{array}{l}\text { University of } \\
\text { Lausanne }\end{array}$ & $\begin{array}{l}\text { Interpreted the data; revised the } \\
\text { manuscript for intellectual content }\end{array}$ \\
\hline $\begin{array}{l}\text { Marie } \\
\text { Théaudin, MD }\end{array}$ & $\begin{array}{l}\text { University of } \\
\text { Lausanne }\end{array}$ & $\begin{array}{l}\text { Interpreted the data; revised the } \\
\text { manuscript for intellectual content }\end{array}$ \\
\hline Carolin Pot, MD & $\begin{array}{l}\text { University of } \\
\text { Lausanne }\end{array}$ & $\begin{array}{l}\text { Interpreted the data; revised the } \\
\text { manuscript for intellectual content }\end{array}$ \\
\hline $\begin{array}{l}\text { Vincent Van } \\
\text { Pesch, MD }\end{array}$ & $\begin{array}{l}\text { Université } \\
\text { Catholique de } \\
\text { Louvain }\end{array}$ & $\begin{array}{l}\text { Interpreted the data; revised the } \\
\text { manuscript for intellectual content }\end{array}$ \\
\hline
\end{tabular}

Appendix (continued)

\begin{tabular}{lll}
\hline Name & Location & Contribution \\
\hline $\begin{array}{l}\text { David Leppert, } \\
\text { MD }\end{array}$ & $\begin{array}{l}\text { University of } \\
\text { Basel }\end{array}$ & $\begin{array}{l}\text { Interpreted the data; revised the } \\
\text { manuscript for intellectual content }\end{array}$ \\
\hline $\begin{array}{l}\text { Christine } \\
\text { Stadelmann, } \\
\text { MD }\end{array}$ & $\begin{array}{l}\text { University of } \\
\text { Göttingen }\end{array}$ & $\begin{array}{l}\text { Analyzed, interpreted the data; } \\
\text { revised the manuscript for intellectual } \\
\text { content }\end{array}$ \\
\hline $\begin{array}{l}\text { Ludwig Kappos, } \\
\text { MD }\end{array}$ & $\begin{array}{l}\text { University of } \\
\text { Basel }\end{array}$ & $\begin{array}{l}\text { Interpreted the data; revised the } \\
\text { manuscript for intellectual content }\end{array}$ \\
$\begin{array}{l}\text { Renaud Du } \\
\text { Pasquier, MD }\end{array}$ & $\begin{array}{l}\text { University of } \\
\text { Lausanne }\end{array}$ & $\begin{array}{l}\text { Interpreted the data; revised the } \\
\text { manuscript for intellectual content }\end{array}$ \\
\hline $\begin{array}{l}\text { Daniel S. Reich, } \\
\text { MD PhD }\end{array}$ & $\begin{array}{l}\text { NIH } \\
\text { Conceptualized study; interpreted the } \\
\text { data; revised the manuscript for } \\
\text { intellectual content }\end{array}$ \\
$\begin{array}{l}\text { Martina } \\
\text { Absinta, MD, } \\
\text { PhD }\end{array}$ & $\begin{array}{l}\text { NIH/Johns } \\
\text { Hopkins }\end{array}$ & $\begin{array}{l}\text { Designed and conceptualized study; } \\
\text { analyzed the data; drafted the }\end{array}$ \\
\hline $\begin{array}{l}\text { Cristina } \\
\text { Granziera, MD, } \\
\text { PhD }\end{array}$ & $\begin{array}{l}\text { University of } \\
\text { Basel }\end{array}$ & $\begin{array}{l}\text { Designed and conceptualized study; } \\
\text { analyzed the data; drafted the } \\
\text { manuscript for intellectual content }\end{array}$ \\
\hline
\end{tabular}

\section{References}

1. Reich DS, Lucchinetti CF, Calabresi PA. Multiple sclerosis. N Engl J Med. 2018; 378(2):169-180.

2. Pitt D, Boster A, Pei W, et al. Imaging cortical lesions in multiple sclerosis with ultra-high-field magnetic resonance imaging. Arch Neurol. 2010;67(7):812-818.

3. Bagnato F, Hametner S, Yao B, et al. Tracking iron in multiple sclerosis: a combined imaging and histopathological study at 7 Tesla. Brain. 2011;134(12):3602-3615.

4. Yao B, Bagnato F, Matsuura E, et al. Chronic multiple sclerosis lesions: characterization with high-field-strength MR imaging. Radiology. 2012;262(1):206-215.

5. Walsh AJ, Lebel RM, Eissa A, et al. Multiple sclerosis: validation of MR imaging for quantification and detection of iron. Radiology. 2013;267(2):531-542.

6. Absinta M, Sati P, Schindler M, et al. Persistent 7-tesla phase rim predicts poor outcome in new multiple sclerosis patient lesions. J Clin Invest. 2016;126(7): 2597-2609.

7. Dal-Bianco A, Grabner G, Kronnerwetter C, et al. Slow expansion of multiple sclerosis iron rim lesions: pathology and $7 \mathrm{~T}$ magnetic resonance imaging. Acta Neuropathol. 2017;133(1):25-42.

8. Absinta M, Sati P, Masuzzo F, et al. Association of chronic active multiple sclerosis lesions with disability in vivo. JAMA Neurol. 2019;76(12):1474-1483.

9. Kaunzner UW, Kang Y, Zhang S, et al. Quantitative susceptibility mapping identifies inflammation in a subset of chronic multiple sclerosis lesions. Brain. 2019;142(1): 133-145.

10. Dal-Bianco A, Grabner G, Kronnerwetter C, et al. Long-term evolution of multiple sclerosis iron rim lesions in 7 T MRI. Brain. 2021:144(3):833-847.

11. Popescu BF, Frischer JM, Webb SM, et al. Pathogenic implications of distinct patterns of iron and zinc in chronic MS lesions. Acta Neuropathol. 2017;134(1):45-64.

12. Absinta M, Sati P, Fechner A, Schindler MK, Nair G, Reich DS. Identification of chronic active multiple sclerosis lesions on 3T MRI. AJNR Am J Neuroradiol. 2018; 39(7):1233-1238.

13. Clarke MA, Pareto D, Pessini-Ferreira L, et al. Value of 3 T susceptibility-weighted imaging in the diagnosis of multiple sclerosis. Am J Neuroradiol. 2020;41(6): 1001-1008.

14. Blindenbacher N, Brunner E, Asseyer S, et al. Evaluation of the "ring sign" and the "core sign" as a magnetic resonance imaging marker of disease activity and progression in clinically isolated syndrome and early multiple sclerosis. Mult Scler J Exp Transl Clin. 2020;6(1):205521732091548.

15. Maggi P, Sati P, Nair G, et al. Paramagnetic rim lesions are specific to multiple sclerosis: an international multicenter 3T MRI study. Ann Neurol. 2020;88(5): 1034-1042.

16. Wisnieff C, Ramanan S, Olesik J, Gauthier S, Wang Y, Pitt D. Quantitative susceptibility mapping (QSM) of white matter multiple sclerosis lesions: interpreting positive susceptibility and the presence of iron: iron and Myelin Content of MS Lesions with MRI. Magn Reson Med. 2015;74(2):564-570.

17. Langkammer C, Liu T, Khalil M, et al. Quantitative susceptibility mapping in multiple sclerosis. Radiology. 2013;267(2):551-559.

18. Absinta M, Sati P, Gaitán MI, et al. Seven-tesla phase imaging of acute multiple sclerosis lesions: a new window into the inflammatory process. Ann Neurol. 2013; 74(5):669-678. 
19. Gillen KM, Mubarak M, Nguyen TD, Pitt D. Significance and in vivo detection of iron-Laden microglia in white matter multiple sclerosis lesions. Front Immunol. 2018; 9:255.

20. Frischer JM, Weigand SD, Guo Y, et al. Clinical and pathological insights into the dynamic nature of the white matter multiple sclerosis plaque: dynamic nature of MS plaque. Ann Neurol. 2015;78(5):710-721.

21. Luchetti S, Fransen NL, van Eden CG, Ramaglia V, Mason M, Huitinga I. Progressive multiple sclerosis patients show substantial lesion activity that correlates with clinical disease severity and sex: a retrospective autopsy cohort analysis. Acta Neuropathol. 2018;135(4):511-528

22. Kuhlmann T, Ludwin S, Prat A, Antel J, Brück W, Lassmann H. An updated histological classification system for multiple sclerosis lesions. Acta Neuropathol. 2017; 133(1):13-24.

23. Popescu BF, Lucchinetti CF. Pathology of demyelinating diseases. Annu Rev Pathol Mech Dis. 2012;7(1):185-217.

24. Ferguson B, Matyszak MK, Esiri MM, Perry VH. Axonal damage in acute multiple sclerosis lesions. Brain. 1997;120(pt 3):393-399.

25. Singh S, Dallenga T, Winkler A, et al. Relationship of acute axonal damage, Wallerian degeneration, and clinical disability in multiple sclerosis. J Neuroinflammation. 2017;14(1):57.

26. Prineas JW, Kwon EE, Cho ES, et al. Immunopathology of secondary-progressive multiple sclerosis. Ann Neurol. 2001;50(5):646-657.

27. Frischer JM, Bramow S, Dal-Bianco A, et al. The relation between inflammation and neurodegeneration in multiple sclerosis brains. Brain. 2009;132(pt 5):1175-1189.

28. Khalil M, Teunissen CE, Otto M, et al. Neurofilaments as biomarkers in neurological disorders. Nat Rev Neurol. 2018;14(10):577-589.

29. Cantó E, Barro C, Zhao C, et al. Association between serum neurofilament light chain levels and long-term disease course among patients with multiple sclerosis followed up for 12 years. JAMA Neurol. 2019;76(11):1359-1366.

30. Disanto G, Barro C, Benkert P, et al. Serum neurofilament light: a biomarker of neuronal damage in multiple sclerosis: serum NfL as a biomarker in MS. Ann Neurol. 2017;81(6):857-870.

31. Thompson AJ, Banwell BL, Barkhof F, et al. Diagnosis of multiple sclerosis: 2017 revisions of the McDonald criteria. Lancet Neurol. 2018;17(2):162-173.
32. Sutter R, Hert L, De Marchis GM, et al. Serum neurofilament light chain levels in the intensive care unit: comparison between severely ill patients with and without coronavirus disease 2019. Ann Neurol. 2021;89(3):610-616.

33. Kurtzke JF. Rating neurologic impairment in multiple sclerosis: an Expanded Disability Status Scale (EDSS). Neurology. 1983;33(11):1444-1452.

34. Roxburgh RH, Seaman SR, Masterman T, et al. Multiple Sclerosis Severity Score: using disability and disease duration to rate disease severity. Neurology. 2005;64(7): 1144-1151.

35. La Rosa F, Abdulkadir A, Fartaria MJ, et al. Multiple sclerosis cortical and WM lesion segmentation at 3T MRI: a deep learning method based on FLAIR and MP2RAGE. NeuroImage. 2020:102335.

36. Absinta M, Nair G, Filippi M, et al. Postmortem magnetic resonance imaging to guide the pathologic cut: individualized, 3-dimensionally printed cutting boxes for fixed brains. J Neuropathol Exp Neurol. 2014;73(8):780-788.

37. Kuhle J, Barro C, Disanto G, et al. Serum neurofilament light chain in early relapsing remitting MS is increased and correlates with CSF levels and with MRI measures of disease severity. Mult Scler. 2016;22(12):1550-1559.

38. Barro C, Benkert P, Disanto G, et al. Serum neurofilament as a predictor of disease worsening and brain and spinal cord atrophy in multiple sclerosis. Brain. 2018;141(8): 2382-2391.

39. Bagnato F, Gauthier SA, Laule C, et al. Imaging mechanisms of disease progression in multiple sclerosis: beyond brain atrophy. J Neuroimaging. 2020; 30(3):251-266.

40. Elliott C, Belachew S, Wolinsky JS, et al. Chronic white matter lesion activity predicts clinical progression in primary progressive multiple sclerosis. Brain. 2019;142(9): 2787-2799.

41. Kornek B, Storch MK, Weissert R, et al. Multiple sclerosis and chronic autoimmune encephalomyelitis. Am J Pathol. 2000;157(1):267-276.

42. Kuhlmann T, Lingfeld G, Bitsch A, Schuchardt J, Brück W. Acute axonal damage in multiple sclerosis is most extensive in early disease stages and decreases over time. Brain. 2002;125(10):2202-2212.

43. Trapp BD, Peterson J, Ransohoff RM, Rudick R, Mörk S, Bö L. Axonal transection in the lesions of multiple sclerosis. N Engl J Med. 1998;338(5):278-285. 


\section{Neurology}

\section{Chronic White Matter Inflammation and Serum Neurofilament Levels in Multiple Sclerosis}

Pietro Maggi, Jens Kuhle, Sabine Schädelin, et al. Neurology 2021;97;e543-e553 Published Online before print June 4, 2021

DOI 10.1212/WNL.0000000000012326

\section{This information is current as of June 4, 2021}

\section{Updated Information \& Services}

References

Citations

Subspecialty Collections

Permissions \& Licensing

Reprints including high resolution figures, can be found at: http://n.neurology.org/content/97/6/e543.full

This article cites 42 articles, 4 of which you can access for free at: http://n.neurology.org/content/97/6/e543.full\#ref-list-1

This article has been cited by 1 HighWire-hosted articles: http://n.neurology.org/content/97/6/e543.full\#\#otherarticles

This article, along with others on similar topics, appears in the following collection(s):

MRI

http://n.neurology.org/cgi/collection/mri

Multiple sclerosis

http://n.neurology.org/cgi/collection/multiple_sclerosis

Information about reproducing this article in parts (figures,tables) or in its entirety can be found online at:

http://www.neurology.org/about/about_the_journal\#permissions

Information about ordering reprints can be found online:

http://n.neurology.org/subscribers/advertise

Neurology ${ }^{\circledR}$ is the official journal of the American Academy of Neurology. Published continuously since 1951, it is now a weekly with 48 issues per year. Copyright Copyright @ 2021 The Author(s). Published by Wolters Kluwer Health, Inc. on behalf of the American Academy of Neurology.. All rights reserved. Print ISSN: 0028-3878. Online ISSN: 1526-632X.

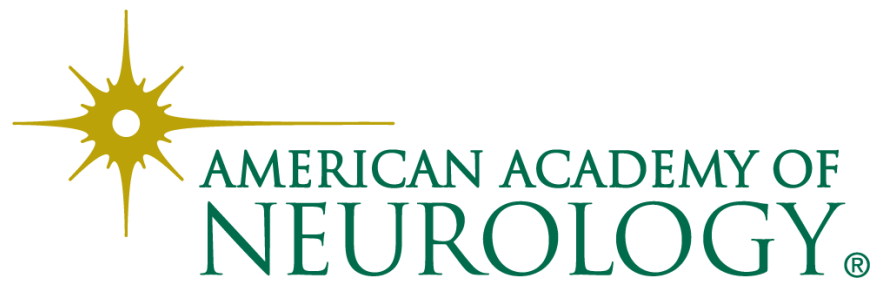

